\title{
Hegemonia e polarização A reconfiguração de forças políticas no município de Porto Alegre (1988 a 2000)
}

Marcia Ribeiro Dias ${ }^{l}$

\section{Introdução}

Ao longo de mais de uma década, o Partido dos Trabalhadores tem governado o município de Porto Alegre, capital do estado do Rio Grande do Sul. Nesse período puderam ser observadas transformações estruturais e comportamentais no cenário político sul-rio-grandense, especialmente em Porto Alegre.

A primeira delas, e também a mais evidente, operou-se na esfera eleitoral. Os eleitores de Porto Alegre, uma capital com forte tradição oposicionista, reelegeram o mesmo partido por três vezes consecutivas para o governo municipal. Assim, a vitória do PT nas eleições de 1988, que prometia ser efêmera, como efêmeras foram as vitórias dos partidos vitoriosos que o antecederam, renovou-se nas eleições de 1992, 1996 e 2000. Quando refiro-me à tradição oposicionista, não me refiro a uma tradição de esquerda, mas a um comportamento contestador que se traduz pela não reeleição de governantes, optando por uma renovação das elites no poder. Foi assim desde a instauração, pelo presidente Getúlio Vargas, dos partidos nacionais em 1945. A última reeleição

${ }^{1}$ Doutora em Ciência Política pelo Instituto Universitário de Pesquisas do Rio de Janeiro (IUPERJ), pesquisadora e professora do Programa de Pós-Graduação em Ciências Sociais da Pucrs. Endereço: mrdias@pucrs.br 
de que se tem notícia antes do feito do PT, foi ainda durante a Primeira República, em 1926, quando Alberto Bins elegeu seu sucessor através do Partido Republicano Sul-Rio-Grandense.

O feito do PT foi romper com uma tradição eleitoral fortemente enraizada através da construção de uma ampla hegemonia social que vem permitindo sua reprodução eleitoral e conseqüente manutenção do poder executivo na capital Porto Alegre. A referida hegemonia social foi construída em torno de um projeto político governamental pautado, ideologicamente, na participação direta da população nos negócios do Estado e, objetivamente, na inversão de prioridades para o investimento em políticas públicas, destinando um maior volume de verbas para os segmentos mais carentes da população. A despeito do intenso debate que tal afirmação pode suscitar, questionando-se a distância entre o que é dito e o que é feito, é este o projeto político que vem sendo ratificado nas urnas de Porto Alegre. É ele, portanto, o responsável pela reprodução eleitoral do PT no município.

O objetivo desse artigo é avaliar em que medida essa hegemonia social construída pelo PT em Porto Alegre vem se traduzindo em uma crescente polarização política, fortalecendo a oposição ao governo e esvaziando o centro político. O fortalecimento da oposição, entretanto, não resolve seu problema estrutural: como superar divergências interpartidárias e unificar estratégias de confronto com o partido governista, consolidando-se como alternativa eleitoral viável. ${ }^{2}$

\section{A construção da hegemonia social}

O resultado das eleições municipais de 1996 colocou a capital gaúcha Porto Alegre em evidência no universo dos municípios brasileiros. Vários fatores contribuíam para sua especificidade nos domínios da política. O primeiro deles, e mais evidente, era o fato de o mesmo partido - o Partido dos Trabalhadores - estar à frente do governo municipal por três gestões consecutivas. Nenhum outro partido até então havia conseguido reeleger-se no Executivo muni-

\footnotetext{
${ }^{2}$ Este artigo é o desdobramento de um dos argumentos contidos em minha tese de doutorado, cujo objetivo foi avaliar efeitos do Orçamento Participativo sobre a Câmara Municipal de Porto Alegre (Dias 2000). É também um texto seminal para o desenvolvimento do projeto de pesquisa "Voto e Participação Política: o impacto do Orçamento Participativo sobre o comportamento eleitoral em Porto Alegre", que atualmente desenvolvo no âmbito do Departamento de Ciências Sociais da Pucrs.
} 
cipal porto-alegrense, muito menos repetir a façanha nas duas eleições subseqüentes.

Não bastasse a aprovação das urnas, pesquisas de opinião revelavam uma ampla aprovação da população sobre o governo, sem que esta aprovação esteja vinculada a segmentos específicos da população. Em dezembro de 1996, a Administração Popular, autodenominação dos governos petistas, era considerada por $72,7 \%$ dos porto-alegrenses como ótima ou boa, $22,3 \%$ a consideravam regular e apenas $5 \%$ avaliaram aquela administração como ruim ou péssima. ${ }^{3}$

Além disso, foi verificado também que, na hora do voto, o que tem contado é o partido, antes do candidato. Prova disto é fornecida a cada novo período de campanha eleitoral no município, quando a população simpatizante dos candidatos do Partido dos Trabalhadores sai às ruas empunhando bandeiras coloridas com o único registro da legenda partidária. $\mathrm{O}$ resultado da eleição de 1996 também foi exemplar nesse sentido, visto que o PT conseguiu se reeleger ainda no primeiro turno - registrando sua hegemonia na cidade - a despeito do perfil "radical de esquerda" do candidato Raul Pont.

A continuidade administrativa através da reeleição é uma especificidade dentro do próprio universo da capital sul-rio-grandense. Não é a reeleição em si o fenômeno que sobressai, mas o seu acontecimento numa seqüência histórico-eleitoral avessa a uma lógica situacionista. A aprovação ao governo, por sua vez, não é um episódio único no Brasil; em diversos municípios brasileiros o quadro de aprovação maciça ao governo vem se repetindo nos dois últimos pleitos eleitorais (1996 e 2000). O fenômeno da ampla aprovação da Administração pela população ganha maior relevância quando agregado aos outros dois acima relacionados, o da reeleição e o do componente partidário da escolha eleitoral, constituindo-se, assim, em um indicador composto da hegemonia do PT em Porto Alegre.

No entanto, o aspecto que mais surpreende, se comparado ao que acontece no restante do país e do mundo, é o da sobreposição do partido como justificativa para a escolha eleitoral. O declínio dos partidos políticos nas democracias contemporâneas é um fenômeno extensivamente estudado nos meios acadêmi-

\footnotetext{
${ }^{3}$ Instituto Amostra - Pesquisas \& Projetos; trabalho de campo realizado entre os dias 2 e 5 de dezembro de 1996, onde 1200 entrevistas foram realizadas, distribuídas por critérios de densidade populacional, em 20 bairros da cidade.
} 
cos da Ciência Política nacional e, principalmente, internacional. Tal declínio está relacionado tanto ao comportamento eleitoral dos indivíduos, na medida em que o partido político tem sido substituído por outros atributos na escolha do eleitor, quanto à redução do potencial de representatividade dos partidos às demandas da sociedade com relação ao Estado. Nesse sentido, estudos eleitorais demonstram que o voto se tornou mais personalista, ou seja, relacionado às características pessoais do candidato, ou fruto de issues (questões da pauta pública) selecionadas pelos candidatos em seu programa eleitoral. ${ }^{4}$

O personalismo na escolha eleitoral é um fenômeno antigo no Brasil, onde as taxas de votos de legenda são sempre inferiores à incidência de votos nominais. As pesquisas de opinião também confirmam a preferência dos eleitores brasileiros por critérios de escolha eleitoral relacionados ao perfil do candidato em detrimento de uma escolha partidária. ${ }^{5}$

O que tem acontecido no cenário político de Porto Alegre, entretanto, vai na contramão desta trajetória observada pelos partidos políticos e, portanto, merece destaque entre os aspectos mencionados como determinantes de uma conjuntura política específica. Em pesquisa de opinião realizada entre agosto/setembro de 1996, comprovou-se uma surpreendente taxa de identificação partidária entre os eleitores de Porto Alegre, em comparação com os de outras capitais brasileiras. Os resultados são os seguintes:

${ }^{4}$ Bartolini e Mair (1990), Cain, Ferejohn e Fiorina (1987), Daalder e Mair (1983), Katz (1997), Lawson e Merkl (1988), Mair (1997), Samuels (1997), Schmidt (1996) são alguns exemplos de estudos recentes empreendidos neste sentido.

${ }^{5}$ Para resultados eleitorais ver encartes da Revista Opinião Pública. Para pesquisas de opinião e personalismo no Brasil, ver Silveira (1998). 
Tabela 1

Identificação partidária - 1996

\begin{tabular}{|c|c|c|c|c|c|}
\hline \multicolumn{2}{|c|}{ Rio de Janeiro } & \multicolumn{2}{|c|}{ São Paulo } & \multicolumn{2}{|c|}{ Porto Alegre } \\
\hline PT & $13 \%$ & PT & $14 \%$ & PT & $46 \%$ \\
\hline PDT & $09 \%$ & PPB & $08 \%$ & PDT & $06 \%$ \\
\hline PMDB & $06 \%$ & PSDB & $05 \%$ & PMDB & $04 \%$ \\
\hline PFL & $05 \%$ & PMDB & $05 \%$ & PSDB & $02 \%$ \\
\hline PSDB & $04 \%$ & Outros & $03 \%$ & PFL & $02 \%$ \\
\hline Outros & $04 \%$ & & & Outros & $02 \%$ \\
\hline $\begin{array}{l}\text { Não têm } \\
\text { preferência }\end{array}$ & $56 \%$ & $\begin{array}{l}\text { Não têm } \\
\text { preferência }\end{array}$ & $58 \%$ & $\begin{array}{l}\text { Não têm } \\
\text { preferência }\end{array}$ & $34 \%$ \\
\hline $\begin{array}{l}\text { Não sabem/não } \\
\text { responderam }\end{array}$ & $03 \%$ & $\begin{array}{c}\text { Não sabem/não } \\
\text { responderam }\end{array}$ & $07 \%$ & $\begin{array}{c}\text { Não sabem/não } \\
\text { responderam }\end{array}$ & $04 \%$ \\
\hline
\end{tabular}

Fonte: JB-Vox Populi. ${ }^{6}$

Como pode-se perceber pelo quadro acima, em Porto Alegre $62 \%$ dos eleitores identificaram-se com algum partido político, com um claro destaque para o PT que, sozinho, arregimentava $46 \%$ das preferências daquele eleitorado. Por outro lado, um número também expressivo de eleitores daquele município $34 \%$ - não possui qualquer preferência partidária. De acordo com os números apresentados, a identificação partidária em Porto Alegre não é genérica, em virtude de não estar distribuída por todo o espectro partidário e sim concentrada na legenda de um único partido - o partido governista. Podemos verificar que o partido colocado em segundo lugar nas preferências do eleitorado distancia-se do PT por uma margem de quarenta pontos percentuais, indicando que a partidarização do jogo político, neste caso, esteja vinculada ao desempenho do partido no governo.

Os quadros relativos aos municípios do Rio de Janeiro e de São Paulo fornecem um excelente contraponto ao caso de Porto Alegre. Nestes municípios verificamos que a identificação partidária dos eleitores é sensivelmente menor do que em Porto Alegre, correspondendo a $41 \%$ no Rio de Janeiro e a $35 \%$ em São Paulo. É possível verificar também que a distribuição das preferências, nos dois

${ }^{6}$ Pesquisa realizada entre os dias 31 de agosto e 3 de setembro, em sete capitais, e entre 11 e 13 de setembro no Rio. Pergunta espontânea. 
casos, é bem mais homogênea do que a apresentada para o município de Porto Alegre. Já a parcela do eleitorado destes municípios que espontaneamente respondeu não ter preferência partidária ultrapassou, em ambos os casos, a marca dos 50\%. É interessante notar que tanto no Rio de Janeiro quanto em São Paulo a preferência eleitoral não foi correspondente à preferência partidária: no primeiro município, o partido governante aprovado nas urnas (PFL) obteve apenas 5\% das preferências do eleitorado, enquanto no segundo, o partido cuja administração também foi aprovada (PPB), fazendo o sucessor, ficou com $8 \%$ das preferências.

Os números acima apontam para a configuração de um sistema multipartidário desequilibrado em Porto Alegre. Arendt Lijphart, ao trabalhar as categorias de Jean Blondel, registra que um sistema partidário pode ser classificado de acordo com a dimensão relativa dos partidos que dele fazem parte. Segundo Blondel, a característica fundamental de um sistema multipartidário desequilibrado é a concentração das preferências eleitorais em torno de um único partido, variando entre 40 e $45 \%$, enquanto outros três ou quatro partidos dividem o restante dos votos (Lijphart 1984: 171).

Vale lembrar que, em 1996, 46\% dos porto-alegrenses afirmaram sua preferência pelo PT, mas cerca de 53\% dos eleitores votaram no partido nas eleições daquele ano. Este tipo de configuração reflete uma hegemonia social em torno de determinado projeto político partidário. Essa hegemonia é percebida e incorporada pelo PT em sua própria campanha eleitoral. ${ }^{7}$

Entretanto, a contrapartida da formação de uma hegemonia social é a articulação de uma contra-hegemonia, polarizando a disputa política eleitoral. É possível perceber que a polarização política no município de Porto Alegre acentuou-se sobremaneira nestes últimos anos, levando as instâncias legislativas e a população local a um posicionamento cada vez mais radical entre os "petistas" (simpatizantes do PT) e os "antipetistas". A própria composição partidária da Câmara Municipal vem refletindo tal tendência. É o que será abordado no próximo segmento.

\footnotetext{
${ }^{7}$ No atual período pré-eleitoral, quando o material de campanha ainda observa uma circulação restrita, encontrou-se uma declaração exemplar nesse sentido: "Nosso projeto deve se afirmar e se renovar permanentemente: só o PT é capaz de suceder e superar o próprio PT".
} 


\section{A polarização político-partidária na Câmara de Vereadores}

A atuação da oposição em sistemas multipartidários tende a produzir efeitos menos significativos sobre o processo governativo do que em sistemas bipartidários. O fundamento dessa correlação é o mesmo que fez Lijphart (1984) afirmar que gabinetes executivos em sistemas parlamentaristas bipartidários possuem maior estabilidade do que em sistemas multipartidários. Ambas as afirmações baseiamse na capacidade de articulação entre os atores políticos para a produção de uma estratégia comum. $\mathrm{O}$ argumento é simples: quanto menor o grau de divergência, maior a probabilidade de produção de consenso. O menor grau de divergência agrega também custos menores para a decisão democrática.

Assim, se sabemos que gabinetes executivos, em sistemas parlamentaristas, dependem da maioria no parlamento para a sua composição, saberemos também que quanto menor for o número de partidos com representação no parlamento, mais unificada será a coalizão governista, com menor grau de custos decisórios e, portanto, mais estável. No limite, se este for um sistema bipartidário, o grau de unidade do gabinete será máximo, visto que sua formação independe de coalizões partidárias: o partido majoritário será responsável pela constituição do governo.

Voltamos, então, à nossa afirmação inicial: quanto menor o número de partidos com representação parlamentar, maior será a probabilidade de unificar a oposição de modo que suas estratégias sejam capazes de afetar o processo governativo, especialmente em sistemas presidencialistas. Se, por um lado, em sistemas parlamentaristas a composição do gabinete executivo dependerá exclusivamente da formação de maioria no parlamento, por outro, em sistemas presidencialistas a formação independente do Executivo, via sufrágio, admite a possibilidade de o partido no Executivo não ter maioria no Legislativo. A possibilidade de a oposição ser majoritária no Legislativo, que não ocorre em sistemas parlamentaristas mas que é relativamente comum em sistemas presidencialistas, reforça a capacidade desta intervir no processo governativo, visto que seu poder de barganha junto ao Executivo aumenta significativamente. Nesses casos, para que o Executivo aprove seus projetos dependerá de acordos, que envolvem concessões, com a oposição ou com segmentos dela. No entanto, essa capacidade de intervenção da oposição será maior ou menor dependendo do número de partidos com representação parlamentar. Observando a mesma lógica que vimos acima, quanto menor o número de partidos na oposição legislativa maior será a sua unidade e, conseqüentemente, mais consistentes suas estratégias de negociação e conflito com o Executivo (Pasquino 1997). 
Desta forma, a coesão da oposição é apresentada como uma decorrência da concentração do sistema partidário; a coesão, por sua vez, será responsável pela disciplina parlamentar necessária a uma ação coordenada que possa ser unificada sob o termo oposicionista. A questão que se coloca é a de avaliar os limites dessa desarmonia entre oposição articulada e sistema multipartidário.

Não há como negar que os custos de articulação da oposição aumentam na proporção do número de atores envolvidos. Por um lado, cada partido de oposição no Legislativo tem razões diferenciadas para discordar da condução do governo pelo Executivo; por outro lado, cada um desses partidos possuirá interesses divergentes a serem alcançados na plataforma governamental. Assim, antes de divergirem do partido governista, os partidos na oposição discordam mutuamente, o que os levam a dispersarem suas ações de confronto, atenuando o efeito das mesmas sobre o Executivo. Além disso, sempre existe a possibilidade de cada partido obter vantagens individuais através de negociações pontuais com o Executivo.

Desta forma, a não ser que uma razão comum os una, os partidos de oposição no Legislativo dificilmente superarão os custos da articulação política a fim de formarem um bloco homogêneo contra o Executivo. Essa razão comum é a "pedra angular" capaz de fazer com que as vantagens coletivas superem perspectivas individuais atreladas às divisões partidárias. E que razão comum é essa? A ineficácia de qualquer estratégia individual, seja de confronto, seja de negociação com o governo, e acima de tudo, a incapacidade de se constituir em alternativa política eleitoral.

Nesses exatos termos está montada a equação política em Porto Alegre. Durante 4 eleições consecutivas o PT saiu vitorioso das urnas. Ao longo dos últimos 13 anos, o Orçamento Participativo constituiu-se na principal marca daquele governo, na razão atribuída ao sucesso administrativo do PT. O fenômeno eleitoral que caracterizou a ascensão do PT neste município não pode ser entendido a não ser à luz do Orçamento Participativo. ${ }^{8}$

A inviabilidade de uma candidatura alternativa está na associação entre o PT e o povo através do OP: de um lado está o povo, do outro - segmentadas em

\footnotetext{
${ }^{8}$ Em pesquisa de opinião realizada pela empresa de consultoria Amostra, publicada em dezembro de $1996,83,1 \%$ dos entrevistados acreditavam que o OP contribuiu para o resultado das eleições daquele ano. Ver também Baquero (1997: 133).
} 
alternativas distintas - estão as elites. Este é o imaginário político que, a despeito de quaisquer conjecturas que falsifiquem esse postulado eleitoral, condicionam grande parte das atitudes políticas naquele município. A partir da declaração de um vereador do PTB, que já foi presidente da Câmara Municipal, é possível obter a confirmação deste postulado: "O PT cresceu porque ele ficou quase numa situação assim: ele representa o povo e os outros não representam nada, os outros representam a si mesmos, as elites, a parte menor da sociedade." (Luiz Braz - vereador PTB)

\section{Quadro 1}

Composição Partidária da Câmara Municipal de Porto Alegre (1989 a 2000)

\begin{tabular}{|l|c|c|c|c|}
\hline \multicolumn{1}{|c|}{ Partido } & $\begin{array}{c}\text { Primeira } \\
\text { Legislatura }\end{array}$ & $\begin{array}{c}\text { Segunda } \\
\text { Legislatura }\end{array}$ & $\begin{array}{c}\text { Terceira } \\
\text { Legislatura }\end{array}$ & $\begin{array}{c}\text { Quarta } \\
\text { Legislatura }\end{array}$ \\
\hline PT & 9 & 10 & 12 & 10 \\
\hline PCB/PPS & 1 & 1 & 1 & - \\
\hline PSB & 1 & - & 2 & 1 \\
\hline PDT & 11 & 9 & 4 & 5 \\
\hline PMDB & 5 & 4 & 2 & 3 \\
\hline PDS/PPB & 4 & 2 & 3 & 4 \\
\hline PFL & 1 & 1 & 1 & 2 \\
\hline PL & 1 & - & - & - \\
\hline PC do B & - & 1 & - & 1 \\
\hline PTB & - & 5 & 5 & 6 \\
\hline PSDB & - & - & 3 & 1 \\
\hline Bancada Governista & 11 & 11 & 15 & 12 \\
\hline "Fiel da Balança" & 11 & 9 & 4 & 5 \\
\hline Oposição & 11 & 13 & 14 & 16 \\
\hline Total de Vereadores & 33 & 33 & 33 & 33 \\
\hline
\end{tabular}

Fontes: Tribunal Regional Eleitoral do Rio Grande do Sul - TRE/RS e Câmara Municipal de Porto Alegre. 
No âmbito do Legislativo porto-alegrense, durante as três primeiras legislaturas, os partidos que compunham a aliança governista eram o PT, o PCB/PPS e o PSB. Em 2000, o PPS saiu da aliança e o PC do B passou a fazer parte da mesma. Na oposição encontravam-se os demais partidos, sendo que o PDT funcionou sempre como o "fiel da balança", votando freqüentemente com o governo ou dividindo-se entre a oposição e a situação. A partir do Quadro 1, é possível perceber a evolução da composição partidária na Câmara nas quatro últimas legislaturas.

Dois tipos de análise podem ser feitos a partir dos dados apresentados no Quadro 1: a primeira, com relação à partilha de poder entre as bancadas de situação e oposição no interior do Legislativo; a segunda, com relação à distribuição partidária dentro de cada uma dessas bancadas.

A dinâmica de forças no Legislativo porto-alegrense revelou uma polarização crescente ao longo dos quatro mandatos, atingindo seu ponto máximo a partir das eleições de 1996, ou seja, na terceira legislatura. Os gráficos dispostos a seguir auxiliarão na composição da análise.

\section{Gráfico 1}

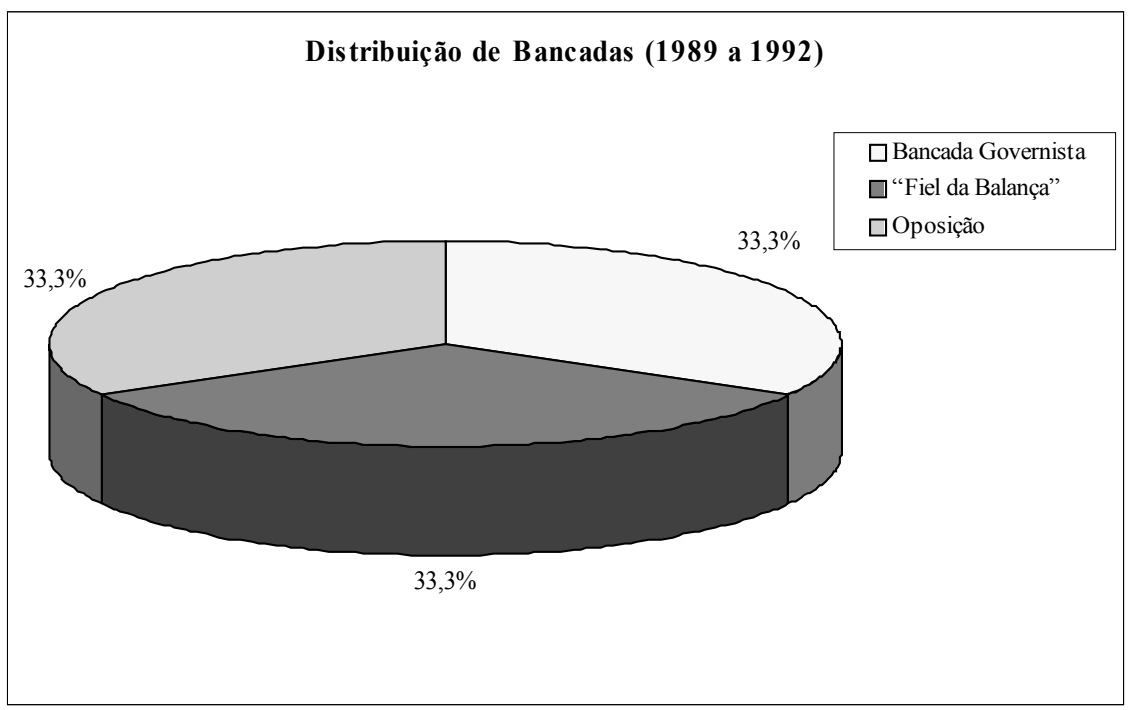


Durante a primeira legislatura a bancada governista contou com 11 cadeiras, enquanto a oposição detinha outras onze; o ponto de equilíbrio entre essas duas bancadas, o PDT, controlava as onze cadeiras restantes. Ou seja, o PDT concentrava, naquele momento, considerável parcela de poder na dinâmica decisória legislativa. Mesmo que o Executivo pudesse fazer negociações pontuais com os demais partidos da oposição, o PDT, pela sua própria posição à esquerda do espectro ideológico, era o partido onde o governo poderia encontrar um maior número de aliados para a aprovação de suas propostas. Essa foi, portanto, uma legislatura bastante equilibrada do ponto de vista ideológico dos partidos que tinham representação na Câmara Municipal. Coincidentemente foi também a legislatura em que registrou-se o mais baixo índice de conflitos entre as esferas Executiva e Legislativa, tal como apontado em minha tese de doutorado (Dias, 2000). ${ }^{9}$

\section{Gráfico 2}

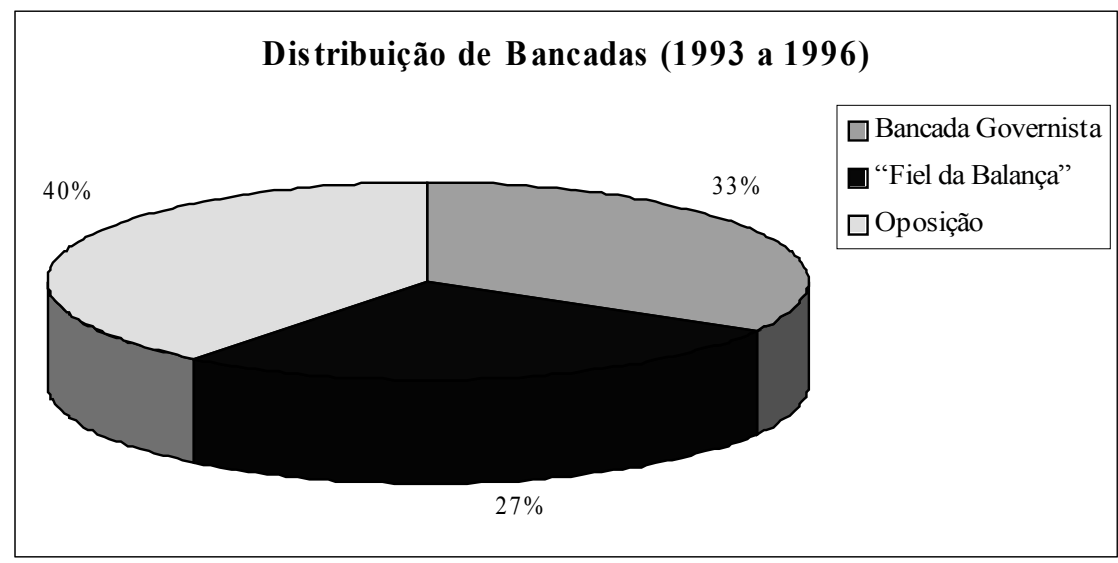

Na segunda Legislatura a configuração da distribuição partidária na Câmara começou a desequilibrar-se, favorecendo a bancada de oposição. A bancada governista manteve o mesmo espaço que ocupou na primeira Legislatura, enquanto o PDT iniciou uma trajetória de declínio, ainda não muito significativa. O mais importante a registrar nessa segunda Legislatura é que as cadeiras perdidas pelo PDT foram totalmente absorvidas pela oposição ao governo. O principal reflexo

${ }^{9}$ Foram considerados indícios de conflito entre Executivo e Legislativo: o aumento do número de vetos do Executivo às decisões do legislativo; o aumento da derrubada de vetos do Executivo pelo Legislativo; o aumento de medidas de controle do Executivo pelo Legislativo; entre outras. 
dessa redistribuição de poder no interior da Câmara Municipal foi a intensificação dos conflitos entre as esferas Executiva e Legislativa, fruto da radicalização de posturas de ambas as partes. As disputas políticas no interior do Legislativo (oposição X situação) também se agravaram sensivelmente. Na análise dos processos orçamentários do período, foi possível constatar diversos movimentos de reação da oposição ao governo no Legislativo, em especial no que diz respeito a vetos. Os vetos do Executivo a alterações feitas por vereadores em projetos de lei passaram a não ser acatados prontamente, como ocorreu na primeira Legislatura, mas ao contrário, ampliaram as discussões no Legislativo e passaram até mesmo a ser derrubados. Contudo, tais movimentos apresentaram-se ainda um tanto incipientes e, principalmente, descoordenados, conjuntura que se alterou significativamente na terceira legislatura.

\section{Gráfico 3}

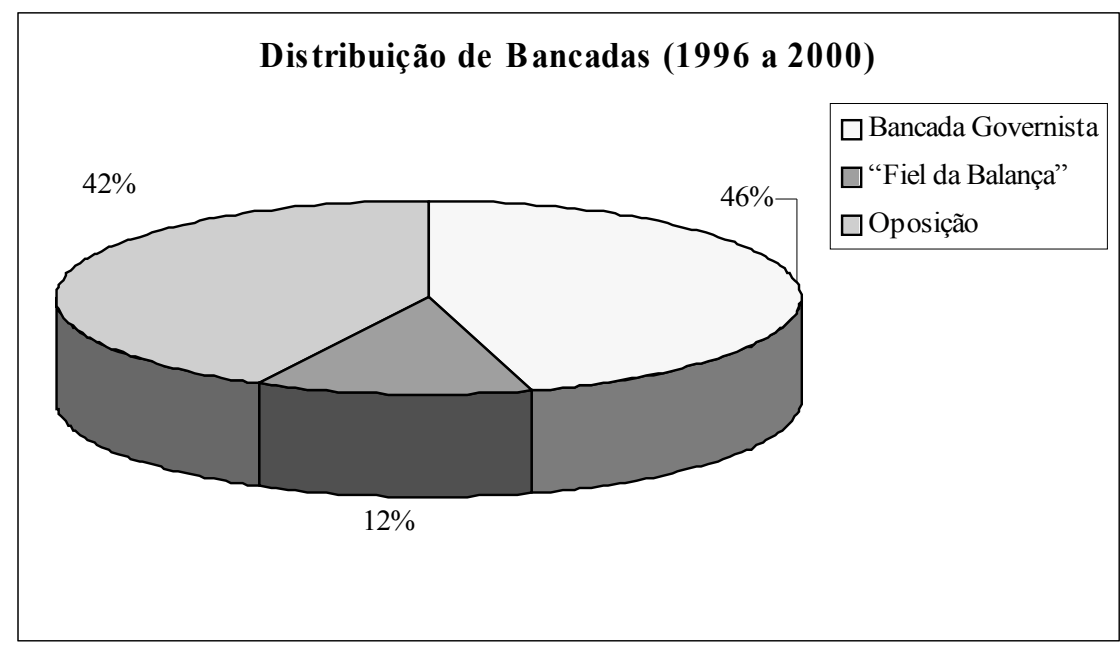

Na terceira Legislatura, a força do PDT sofreu uma redução drástica: de suas 11 cadeiras iniciais, conquistadas nas eleições de 1988, reduzidas para 9 nas eleições de 1992, o partido saiu das eleições de 1996 com apenas 4 cadeiras. Em contrapartida, tanto a bancada governista quanto a de oposição aumentaram de tamanho, reforçando ainda mais a polarização Legislativa, na medida em que o ponto de equilíbrio entre ambas, a postura do PDT, passava a ser cada vez menos decisivo para o resultado das votações. Vale ressaltar que, desta vez, a gran- 
de vitoriosa foi a bancada governista que absorveu quase todas as perdas do PDT: cerca de $87 \%$ das cadeiras que este partido controlava na segunda Legislatura foram para o PT e seus aliados. O enfraquecimento do ponto de equilíbrio entre as bancadas de situação e oposição resultou no esvaziamento do centro político, polarizando intensamente a dinâmica legislativa.

Em 1997, um novo mandato do PT estava se iniciando e principalmente os vereadores mais antigos na Casa Legislativa já sabiam o que estava por vir. Em primeiro lugar estava a atitude do Executivo com relação aos vereadores, recusando-se a negociar questões de ordem orçamentária. Desde a criação do Orçamento Participativo, o Executivo vinha adotando um tipo de resposta padrão aos vereadores que solicitavam "providências": sugeria a eles que remetessem seus pedidos àquela instância. O Orçamento Participativo era, então, segundo o Executivo, o principal órgão decisório da aplicação das verbas públicas do município e quaisquer projetos deveriam passar necessariamente por essa instância. Como os vereadores se recusavam a dirigir-se ao OP, seus "pedidos de providências" ficavam inviabilizados.

O Executivo simplesmente quer se despojar do clientelismo político; eu acho que tem vereadores que fazem o clientelismo político, pedem tudo, fazem ofícios, atiram tudo para o Executivo e, na verdade, o Executivo trabalha para partidos aos quais ele nem pertence. E ele, querendo se desvencilhar disso, inventou o Orçamento Participativo. E anula, quando eu faço um pedido. (...) Eu tenho a impressão que o Orçamento Participativo tira da cidade $30 \%$, vamos dar um número aleatório, da empolgação do Legislativo em benefício do Executivo. Eu te digo isso sem nenhuma restrição, os vereadores não trabalham do lado, trabalham às vezes até contra, mas trabalham de má vontade, com críticas, sempre procurando a oposição. Por que isso? Uma das coisas é o Orçamento Participativo. Eu acho que esse OP devia ser reduzido à sua verdadeira grandeza: é um departamento do Executivo. E o Executivo devia ter ouvidos às sugestões que os vereadores fazem e responder a elas fazendo ou dizendo por que não faz. (...) Os poderes estão separados, j'accuse - eu acuso! (Pedro Américo Leal - Vereador PPB)

Neste caso, não é que o Executivo se recusasse a qualquer tipo de negociação pontual com partidos de oposição; isso acontecia principalmente na área orçamentária e em virtude do Orçamento Participativo. O próprio vereador Pedro Américo Leal afirmou ser um dos poucos vereadores que não podiam se queixar do Executivo porque este ainda ouvia suas sugestões, mas ofereceu um panorama geral da situação da oposição no discurso em destaque acima. 
O que passou a ocorrer na Câmara a partir da terceira legislatura foi uma maior articulação entre os partidos de oposição a fim de contrariar decisões do Executivo, como no caso da derrubada de vetos. Os mecanismos de reação da oposição no Legislativo, que se manifestaram de forma ainda muito incipiente durante a segunda legislatura, começaram a se fortalecer na terceira, e se consolidam na atual. O quadro da distribuição de cadeiras na atual Legislatura é bastante coerente com o fortalecimento do poder da oposição no município de Porto Alegre.

\section{Gráfico 4}

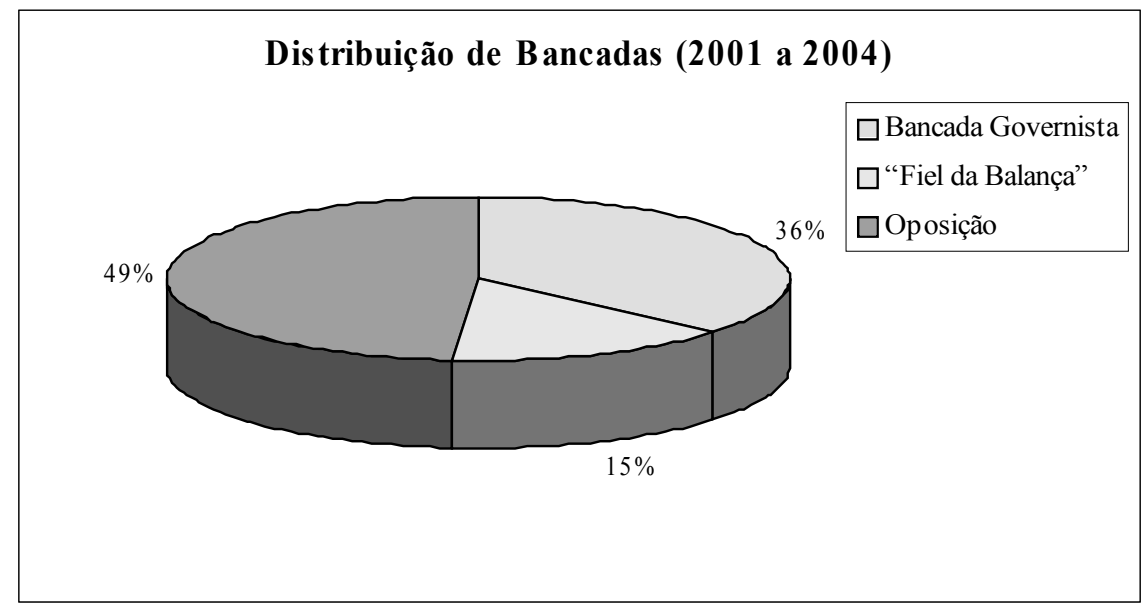

A distribuição de forças políticas no interior da Câmara, nessa Legislatura, alterou-se novamente. Desta vez foi a bancada governista quem perdeu espaço no Legislativo Municipal: cerca de $20 \%$ de suas cadeiras foram para os partidos de oposição e o PDT, principal adversário do PT na eleição para prefeito de 2000. É possível que a hegemonia "petista" na capital do Rio Grande do Sul já esteja dando sinais de desgaste. Se compararmos o quadro atual com a conjuntura de 1996, certamente verificaremos que a preferência pelo PT como alternativa política eleitoral, embora ainda seja majoritária, já não é mais a mesma.

No entanto, a composição interna, em termos partidários, da bancada de oposição agrega um elemento complicador para esta análise. Primeiramente, verificamos que o número de partidos de oposição com representação legislati- 
va aumentou do segundo para o terceiro mandato, estabilizando-se no quarto. Assim, a fragmentação partidária da oposição, que na primeira e segunda Legislaturas contava com 4 partidos, ampliou para 5 partidos nas duas Legislaturas seguintes. De acordo com o argumento teórico, desenvolvido no início desse tópico, a capacidade de articulação da oposição contra o Executivo deveria ter se debilitado com o aumento de sua fragmentação interna. O que observamos, entretanto, é um movimento de trajetória inversa: a partir do segundo mandato a oposição ampliou sua capacidade de articulação e empreendeu vitórias significativas com relação ao Executivo. Resta questionar o que explicaria esse comportamento dos vereadores de oposição, que segue na contramão do argumento teórico. Com base nos gráficos a seguir será possível visualizar melhor as alterações sofridas pelas bancadas de cada um dos partidos ao longo do tempo e, conseqüentemente, esclarecer por que o comportamento da oposição não refletiu o argumento teórico.

\section{Gráfico 5}

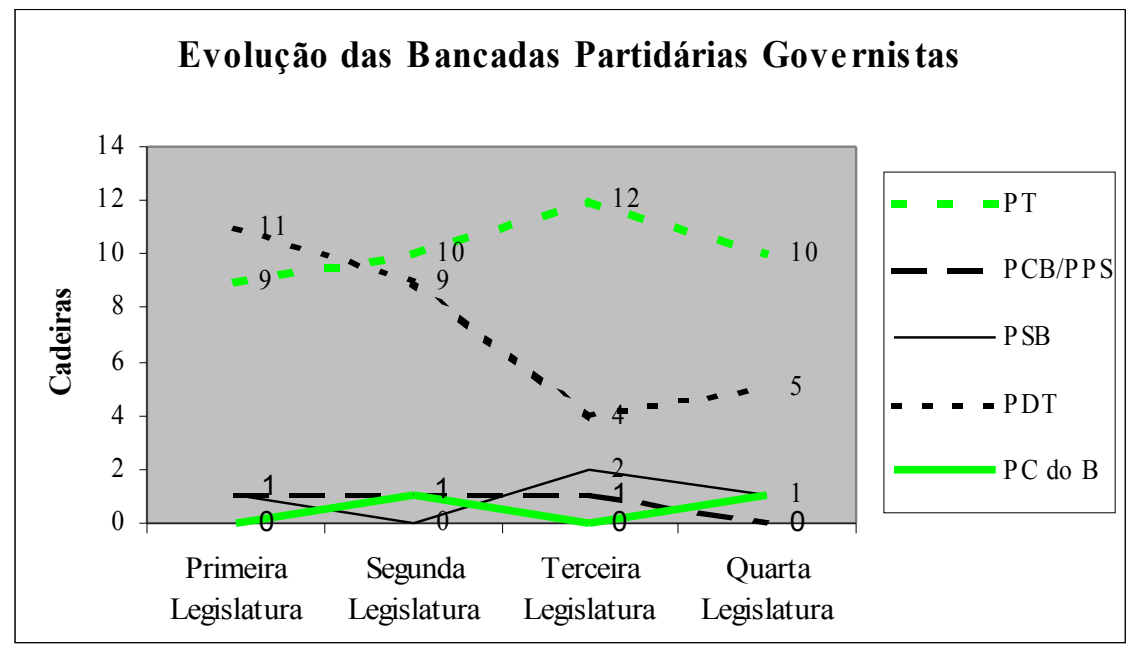




\section{Gráfico 6}

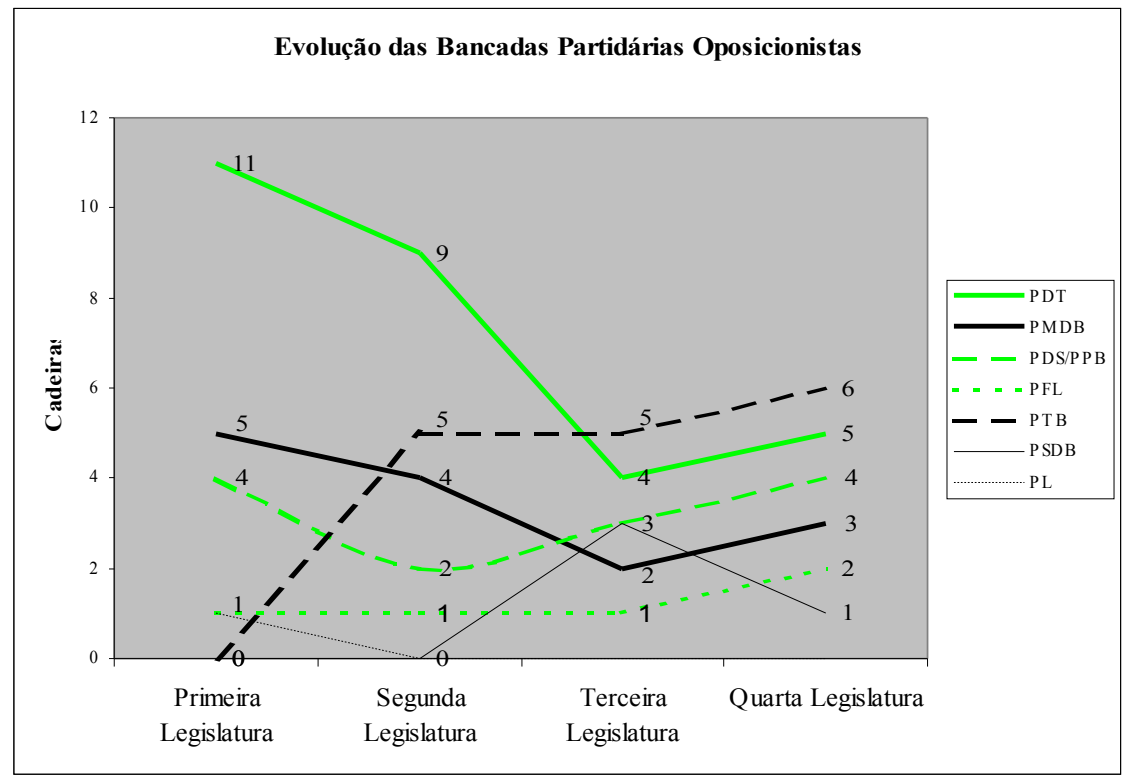

Os gráficos acima demonstram a evolução de cada uma das bancadas partidárias, sua dimensão em cada um dos mandatos legislativos e, conseqüentemente, sua capacidade de influenciar os resultados do processo decisório. O primeiro agrega os partidos que estiveram em aliança com o governo, enquanto o segundo agrega os partidos que formam a oposição. A curva de desempenho do PDT aparece nos dois gráficos a fim de demonstrar a ambigüidade deste partido, ora votando com o governo, ora com a oposição. ${ }^{10}$

Durante a primeira Legislatura, como vimos, foi possível registrar um pronunciado equilíbrio entre as bancadas de situação e oposição, além de um acentuado poder de barganha para o PDT que, sozinho, controlava um terço das cadeiras na Câmara. A partilha do poder dentro de cada uma das bancadas, no entanto, era bem diferente. A bancada governista contava com três partidos, dois deles pouco expressivos (PCB e PSB), visto que detinham apenas uma cadeira

${ }^{10}$ Quando refiro-me a curva de desempenho desejo enfatizar que o número de cadeiras ocupadas pelos partidos em cada mandato reflete, antes de tudo, o desempenho eleitoral de cada um deles por eleição. 
cada um; o desequilíbrio na distribuição de poder no interior dessa bancada, favorecia as decisões do partido no Executivo (PT). Já a bancada de oposição apresentou-se mais fragmentada e equilibrada: quatro partidos partilhavam o poder decisório em seu interior; dois deles (PFL e PL), também com uma cadeira cada um, contavam pouco no processo decisório. PMDB e PDS apresentavam um peso relativo muito mais significativo, comandando a oposição no Legislativo.

Vale ressaltar que ao fazer referência à "bancada de oposição" não se pretende alegar qualquer unidade nas ações oposicionistas. Muito pelo contrário; nesse momento, os partidos de oposição encontravam-se desarticulados e estabeleciam estratégias de negociação ou conflito com o partido governista de forma isolada, raramente estabelecendo contatos de solidariedade horizontal. Como vimos acima, o principal problema da oposição nas democracias contemporâneas é encontrar a unidade necessária de modo a tornar suas ações efetivas. ${ }^{11}$

Do primeiro para o segundo mandato, algumas alterações significativas ocorrem na composição partidária da Câmara Municipal. Cinco partidos perdem cadeiras: PL e PSB perdem as únicas cadeiras que possuíam e, conseqüentemente, a representação na Câmara; o PMDB perde uma, enquanto o PPB e o PDT perdem duas cada um. Ou seja, um total de sete cadeiras legislativas mudaram de mãos entre a primeira e a segunda legislatura. A grande surpresa das eleições de 1992 foi a formação na Câmara de uma "super-bancada" de cinco cadeiras pelo PTB, que na Legislatura anterior não possuía sequer representação. Dada sua posição no espectro político-ideológico, é possível supor que o PTB tenha "herdado" as cadeiras do PL, PMDB, PPB e uma das do PDT. O PT ganhou mais uma cadeira, provavelmente oriunda do PSB, seu partido aliado. O PC do $\mathrm{B}$ também conquistou uma cadeira, que pode ter vindo do PDT. Nesse momento, o PC do B não fazia parte da "Frente Popular" (aliança governista) e durante esta Legislatura posicionou-se diversas vezes contra o governo.

A lógica na transferência de cadeiras, acima descrita, é obviamente hipotética. Não há como ter certeza da origem e do destino dos votos que reconfiguraram a distribuição partidária na Câmara. O que importa registrar nesse momento

${ }^{11}$ A literatura acadêmica contemporânea pouco se ocupa do problema das "oposições" em sistemas representativos. Em geral, restringem sua análise à atuação governamental. Um dos raros trabalhos que se ocupam dessa temática é o acima citado La oposición en las democracias contemporaneas, de Gianfranco Paquino. 
é a profunda coerência ideológica do novo desenho de distribuição de forças políticas no Legislativo com relação ao anterior. Mas, algumas modificações podem ser apontadas.

Primeiramente, o PT ficou praticamente sozinho na bancada governista, unificando-a ainda mais: além de suas 10 cadeiras, somente o PPS detinha uma cadeira nesta bancada. Já a oposição ficou mais fragmentada, não pelo número de partidos com representação, mas pela força relativa de cada um deles. O PTB surgiu nesse momento com uma poderosa bancada de cinco vereadores; em seguida estava o PMDB com quatro vereadores; o PPB, apesar da perda de duas cadeiras, estava representado por duas figuras importantes pelo tempo de vivência na Casa e, conseqüentemente, experiência nos trâmites legislativos: João Dib e Pedro Américo Leal. O PFL continuou com uma cadeira e a fragilidade anterior. O poder já não estava mais tão equilibrado na bancada oposicionista como no primeiro mandato, mas ainda não registrava desequilíbrio, visto que nenhum dos partidos que a compunha predominava sobre os demais.

É possível imaginar que o equilíbrio na partilha de poder entre os partidos da oposição dificultasse a unidade de suas ações, propiciando, novamente, que suas estratégias de negociação e conflito com o partido governista se individualizassem. Mas, nessa Legislatura já ficaram perceptíveis algumas estratégias de reação por parte da bancada oposicionista, conforme apontado acima, talvez em virtude do surgimento da bancada do PTB, mais disposta a um enfrentamento com o Executivo.

A configuração de forças partidárias no interior do Legislativo municipal sofreu novas alterações a partir das eleições de 1996. A mais enfática delas foi a perda de cinco cadeiras pelo PDT, registrando a decadência do centro político. $\mathrm{O}$ PMDB também continuou sua trajetória de declínio, perdendo mais duas cadeiras. Com mais a perda da cadeira pelo $\mathrm{PC}$ do $\mathrm{B}$, foi um total de oito cadeiras que mudaram de partidos do segundo para o terceiro mandato. Destas, a maior parte foi para a bancada governista e uma parte menor para a oposição, sintoma da polarização crescente, não apenas na esfera legislativa, mas também na opção do eleitorado.

A trajetória da transferência de cadeiras, neste caso, é um pouco mais complicada em função de duas dissidências ocorridas na bancada do PT: as transferências do vereador Antônio Hohlfeldt para o PSDB (ocorrida ainda na Legislatura anterior) e do vereador Hélio Corbelini para o PSB. A reeleição do verea- 
dor Hohlfeldt, que já se encontrava no PSDB nas eleições de 1996, implicou em uma reeleição para o PSDB, significando que este partido não ganhou três novas cadeiras e sim duas; uma delas certamente veio do PT, as outras duas provavelmente do PMDB (seguindo a lógica da coerência ideológica). Das duas cadeiras ganhas pelo PSB nessa Legislatura, uma foi fruto do ingresso do vereador Corbelini em suas hostes, ainda no início do mandato. A outra, seguindo novamente alguma coerência ideológica, pode ter vindo da perda sofrida pelo PC do B.

Eleitoralmente falando, o PT ganhou quatro novas cadeiras em 1996, tendo uma delas se transferido para o PSB, com a saída de Hélio Corbelini do partido, e outra compensado a saída de Antônio Hohlfeldt. Por isso, no gráfico, a bancada do PT aumentou de 10, na segunda legislatura, para 12 na terceira. As novas cadeiras do PT e o ganho de mais uma cadeira pelo PPB, provavelmente, tiveram uma origem comum: a perda das cinco cadeiras pelo PDT.

Internamente, as bancadas governista e oposicionista sofreram algumas transformações. Na primeira o desequilíbrio, registrado pela predominância do PT, continuou, apesar do PSB ter obtido representação novamente (PT: 12; PSB: 2; PPS: 1). Na bancada de oposição a fragmentação aumentou numericamente: cinco partidos disputavam o poder neste segmento. O PTB manteve sua relevância com cinco cadeiras; o PSDB e o PPB ocuparam três cadeiras cada um; o PMDB, apesar da queda na representação, manteve ainda duas cadeiras; e o PFL manteve sua cadeira anterior. Assim, pelo menos quatro partidos apresentavam relevância no quadro oposicionista daquele período. O enfraquecimento da oposição em virtude de sua fragmentação, entretanto, não ocorreu. $\mathrm{O}$ que pode ser observado nas movimentações e votações legislativas do período é um progressivo enrijecimento de posturas contra os projetos do Executivo, uma maior disposição para o conflito e uma maior articulação entre os partidos de oposição. $\mathrm{O}$ responsável por esse resultado, ou seja, a radicalização de posturas oposicionistas, foi provavelmente o esvaziamento do centro político, traduzido pelo declínio dos partidos de posturas mais moderadas e o fortalecimento de partidos mais dispostos ao enfrentamento político com o Executivo.

Finalmente, o quadro da distribuição partidária no quarto mandato aponta para novas perspectivas, registrando o primeiro declínio da bancada governista na Câmara. A volatilidade eleitoral nesse ano foi menor: apenas seis cadeiras mudaram de mãos entre a terceira e a quarta Legislatura. Dois terços das perdas ocorreram na bancada governista: o PT perdeu duas cadeiras, o PSB uma, e o 
PPS, que rompeu a aliança com a Frente Popular em 2000, perdeu a única cadeira que tinha, quando o vereador Lauro Hagemann decidiu não se candidatar. Os ganhos desta vez foram pulverizados: seis partidos conquistaram uma nova cadeira (PC do B, PDT, PMDB, PFL, PTB e PPB). Neste caso, é difícil fazer um acompanhamento, mesmo que hipotético, das transferências de cadeiras entre partidos. É possível imaginar que a cadeira obtida pelo PC do B, que neste ano entrou para a aliança da Frente Popular, tenha vindo dos votos que deixaram de ser dados para o PT, PSB ou PPS. As cadeiras perdidas pelo PSDB (duas) podem ter ido para qualquer um dos outro cinco partidos que aumentaram sua votação. A única coisa que se pode ter certeza é que votos que antes eram dados para a aliança governista migraram para a oposição.

O quadro de distribuição de forças na bancada governista não sofreu alterações significativas, mantendo o desequilíbrio através da predominância do PT. A composição partidária da oposição, manteve a fragmentação numérica do período anterior e a distribuição de poder ainda encontra-se equilibrada, mas o PTB lidera essa bancada com seis das cadeiras legislativas. A bancada de oposição tornou-se praticamente majoritária na atual Legislatura, concentrando 16 das 33 cadeiras da Câmara de Vereadores. Se considerarmos que o PDT vota freqüentemente com a oposição, é possível afirmar que a condição majoritária desta última é incontestável. O jogo no Legislativo não está mais dividido; ele pende claramente para a oposição.

\section{Considerações finais}

A renovação do governo do PT na prefeitura de Porto Alegre, a partir das eleições de 2000, registra a continuidade de sua hegemonia social, mas o resultado das eleições legislativas daquele mesmo ano deu mostras de seu enfraquecimento, ao menos no que se refere à representação parlamentar.

Segundo Baquero (1997), o PDT e o PMDB foram os partidos que mais perderam eleitores para o PT em Porto Alegre nos últimos anos. Baseado nos resultados de pesquisas realizadas pelo Núcleo de Pesquisas Eleitorais do Rio Grande do Sul (Nupergs), Baquero constatou a transferência da identificação partidária dos porto-alegrenses do PDT e do PMDB para o PT, entre 1985 e 1996. Em 1985 o PDT era identificado como partido preferido por $27,7 \%$ dos gaúchos da capital, enquanto o PMDB contava com 20,9\% desta identificação; o 
PT, naquele momento, contava com apenas $6,4 \%$ das preferências partidárias em Porto Alegre. Em 1996, este quadro havia se alterado por completo: a preferência partidária pelo PDT foi reduzida para $4,7 \%$, a preferência pelo PMDB restringia-se a apenas $2,2 \%$, enquanto o PT acumulava uma preferência de $40,9 \%$ dos porto-alegrenses (Baquero 1997: 132).

Isso explica, obviamente, o declínio desses dois partidos na representação parlamentar municipal. Explica também o crescimento da base Legislativa do PT. Entretanto, esses índices não são suficientes para se afirmar a migração da identificação partidária do PDT e PMDB para o PT. ${ }^{12}$ Vale ressaltar que a soma das perdas legislativas desses dois partidos, entre 1989 e 1996, não foram equivalentes à soma dos ganhos do PT. A parcela dos votos perdidos pelo PDT e pelo PMDB que não foi para o PT dirigiu-se para a oposição a este partido, em geral, à oposição mais obstinada.

A polarização política no município, constatada empiricamente na evolução da distribuição partidária na Câmara Municipal, carece de uma maior precisão na definição das identidades de cada uma das suas extremidades.

De um lado, está claro, são os simpatizantes do PT: vai desde o filiado ao partido, passando pelo empolgado que agita suas bandeiras em tempo de eleição, até aquele que simplesmente aprova a sua administração e, por isso, vota nele. $\mathrm{O}$ primeiro é o convicto; o segundo, o apaixonado; o terceiro, o pragmático.

Mas a outra extremidade não está tão clara. Esta não é feita pela identificação com um partido político que se opõe ao PT e, nesse sentido, difere-se da tradicional lógica bipolar admirada pelos gaúchos: são ximangos e maragatos, colorados e gremistas, entre outros. "Petistas" e "anti-petistas" não obedecem à mesma classificação bipolar em função do caráter difuso da identidade dos "antipetistas". Essa identidade se afirma, exclusivamente, pela negação, ou seja, pela rejeição ao projeto político do PT. Não comporta um projeto alternativo e, portanto, pulveriza-se entre os diversos partidos que assumem o discurso da oposição, não conseguindo constituir uma alternativa eleitoral viável.

A identidade social construída pelo PT, em função de valores como democracia e participação popular, é difícil de combater retoricamente, e por isso é hegemônica. O que os partidos de oposição têm feito não é combater os valores

\footnotetext{
${ }^{12}$ A preferência pelo PT pode ser oriunda de eleitores que antes não possuíam qualquer preferência partidária.
} 
assumidos pelo PT, mas sim incorporá-los, criticando as práticas governamentais do partido e seus resultados. No entanto, nenhum deles tem sido bem sucedido em deixar a dimensão puramente crítica e construir um projeto alternativo convincente o bastante para unificar os "anti-petistas" e dar a eles uma identidade própria. Exemplar, nesse sentido, é o slogan do PFL na campanha deste ano: "PFL: ao lado do povo, contra o PT". O argumento central, contido na propaganda do PFL é de que o PT engana o povo ao dizer que está ao seu lado. Com isso pretende debilitar a imagem social do PT pelo desmonte da identidade por este assumida. Em seguida, o PFL assume sua "identidade anti-petista"; em nenhum momento da propaganda aqui referida, o partido diz o que é, ou seja, não evidencia sua identidade, senão pelas acusações do que o PT não é.

Como resultado, o que tem acontecido é o aprofundamento das tensões entre os dois pólos do eixo das preferências eleitorais em Porto Alegre e uma negação da política de conciliação entre governo e oposição. No limite, a resultante desse processo pode ser o conflito social e a ingovernabilidade. Em contrapartida, é impossível não notar que os processos eleitorais nesta capital têm fascinado seus observadores pela empolgação dos eleitores: a cidade se transforma em um "mar" de bandeiras coloridas que promovem as candidaturas em disputa, em um raro sinal de vitalidade democrática. $\mathrm{O}$ fortalecimento da oposição também não pode ser encarado como um problema em si. Pelo contrário, articulada e disposta a negociar, a oposição fortalecida pode fazer em Porto Alegre o que é muito raro em sistemas onde o Executivo predomina na balança entre os Poderes: influenciar o processo governativo e ampliar o grau de representatividade das decisões.

O objetivo desse texto foi traçar um diagnóstico da evolução do quadro eleitoral e da distribuição de poder político em Porto Alegre, identificando a cristalização de posturas, mas sobretudo a vitalidade da dinâmica política em curso no município. 


\section{Referências bibliográficas}

Baquero, Marcello (1997). Novos padrões de comportamento eleitoral: pragmatismo nas eleições municipais de 1996 em Porto Alegre. In: —— . (Org.). A lógica do processo eleitoral em tempos modernos. Porto Alegre/Canoas: Editora da Ufrgs/La Salle de Ensino Superior.

Bartolini, Stefano; Mair, Peter (1990). Identity, competition and electoral availability: the stabilisation of European electorates, 1885-1995. Cambridge: Cambridge University Press.

Blondel, Jean (1995). Comparative government: an introduction. 1. ed. Cambridge: Prentice Hall/ Harvester Wheatsheaf.

Cain, Bruce; Ferejohn, John; Morris, Fiorina (1987). The personal vote: constituency service and electoral independence. Cambridge: Harvard University Press.

Daalder, H.; Mair, P. (1983). Western European party system: continuity and change. London: Sage Publications.

Dias, Marcia R. (2000). Na encruzilhada da teoria democrática: efeitos do Orçamento Participativo sobre a Câmara Municipal de Porto Alegre. Tese (doutorado). Rio de Janeiro: Iuperj.

Katz, Richard (1997). Democracy and elections. Oxford: Oxford University Press.

Lawson, Kay; Merkl, Peter (1988). When parties fail: emerging alternative organizations. Princeton: Princeton University Press.

Lijphart, Arend (1989). As democracias contemporâneas. Lisboa: Gradiva.

Mair, Peter (1997). Party system change. Oxford: Oxford University Press.

Pasquino, Gianfranco (1997). La oposición en las democracias contemporaneas. Buenos Aires: Eudeba.

Samuels, David (1997). Determinantes do voto partidário em sistemas eleitorais centrados no candidato: evidências sobre o Brasil. Dados, v. 40, n. 3, p. 493-533.

Schmidt, Manfred (1996). When parties matter: a review of the possibilities and limits of partisan influence on public policy. European Journal of Political Research, v. 30, n. 2, p. 155-183.

Silveira, Flávio E. (1998). A decisão do voto no Brasil. Porto Alegre: Edipucrs. 